\title{
Correction to: Neurexin 3 transmembrane and soluble isoform expression and splicing haplotype are associated with neuron inflammasome and Alzheimer's disease
}

Akitoyo Hishimoto1', Olga Pletnikova², Doyle Lu Lang ${ }^{3}$, Juan C. Troncoso², Josephine M. Egan ${ }^{3}$ and Qing-Rong Liü $^{3 *}$

Correction to: Alzheimers Res Ther (2019) 11:28 https://doi.org/10.1186/s13195-019-0475-2

Following publication of the original article [1], the authors reported that Fig. 6 contains a mistake. The Fig. $6 \mathrm{f}$ is a duplicate of Fig. 6e of Braak 5.

The correct Fig. 6f is shown below.

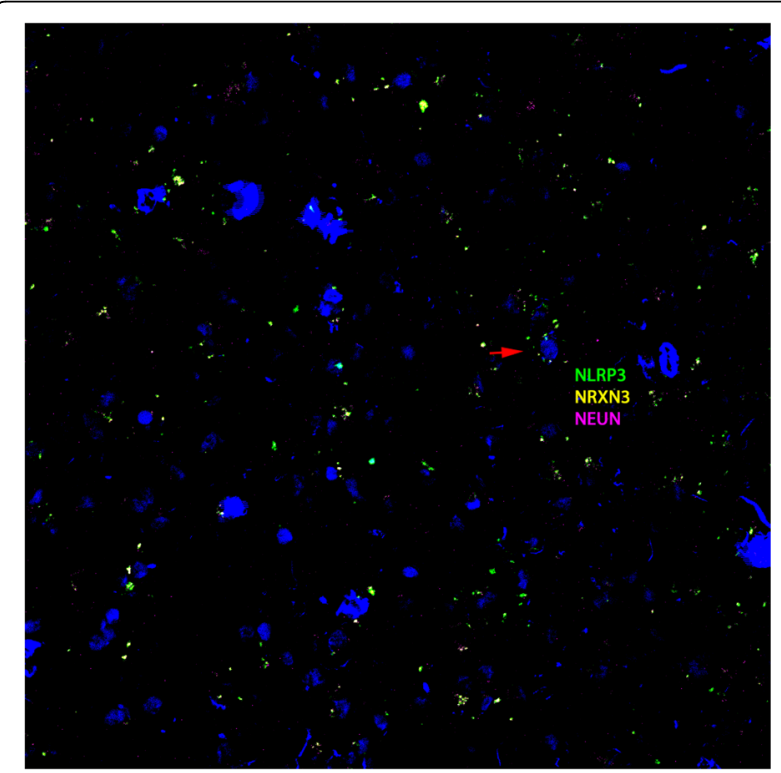

Fig. $\mathbf{6}$ a-h RNAscope in situ hybridization of control and AD brain samples with different BRAAK numbers (a). Green represents NLRP3, yellow NRXN3, and magenta NEUN. The red arrow indicates colocalization of three probes in the same cell. H-score correlations of NRXN3 and NLRP3 intensities with BRAAK numbers (b)

\section{Author details}

'Department of Psychiatry, Kobe University Graduate School of Medicine, 7-5-1 Kusunoki-Cho, Chuo-Ku, Kobe 650-0017, Japan. ${ }^{2}$ Departments of Pathology, Neuropathology Division, Johns Hopkins University School of Medicine, 600 North Wolfe Street, Baltimore, MD 21205, USA. ${ }^{3}$ Lab of Clinical Investigation, NIA-NIH, 251 Bayview Blvd, Baltimore, MD 21224, USA.

Published online: 07 May 2019

\section{Reference}

1. Hishimoto A, et al. Neurexin 3 transmembrane and soluble isoform expression and splicing haplotype are associated with neuron inflammasome and Alzheimer's disease. Alzheimers Res Ther. 2019;11:28 https://doi.org/10.1186/s13195-019-0475-2.

* Correspondence: qliu@mail.nih.gov

${ }^{3}$ Lab of Clinical Investigation, NIA-NIH, 251 Bayview Blvd, Baltimore, MD 21224, USA

Full list of author information is available at the end of the article 